\title{
Response to Trans-2017-0772.R1.
}

We would like to thank D. Johnson et al. for their professional review and valuable comments on our paper entitled 'The effect of a standard whole blood donation on oxygen uptake and exercise capacity: a systematic review and meta-analysis. ${ }^{1}$ They claimed that the meta-analysis of the effects on $\mathrm{VO}_{2 \max }$ 24-48 hours after whole blood donation would have been more robust by analyzing studies of similar blood volumes (i.e. $430-450 \mathrm{~mL}$ versus $500 \mathrm{~mL}$ ). In addition, the reviewers had concerns whether the studies by Ekblom et al. ${ }^{2}$ and Foster et al. ${ }^{3}$ should be included in this analysis and they found 2 errors in the data-extraction.

We agree with the reviewers (except excluding the study by Foster et al. ${ }^{3}$ ) and have performed additional analyses to address their concerns, which however did not impact our previous conclusions.

Firstly, we conducted a subgroup analysis regarding $\mathrm{VO}_{2 \max }$ (24-48 hours after donation) by separating the studies that withdrew $430-450 \mathrm{~mL}$ compared to those that withdrew $500 \mathrm{~mL}$ (figure 1). This analysis confirms the reviewer's point by showing that standard whole blood donations of $430-450 \mathrm{~mL}$ or $500 \mathrm{~mL}$ both result in a statistically significant reduced $\mathrm{VO}_{2 \max } 24-48$ hours after donation and this effect is more pronounced in the studies that withdrew $500 \mathrm{~mL}$ of whole blood ($2.9 \mathrm{~mL} \mathrm{O} / \mathrm{min} / \mathrm{kg}$ (or $6 \%$ decrease) for $430-450 \mathrm{~mL}$ vs $-4.33 \mathrm{~mL} \mathrm{O} / \mathrm{min} / \mathrm{kg}$ (or $10 \%$ decrease) for $500 \mathrm{~mL})$.

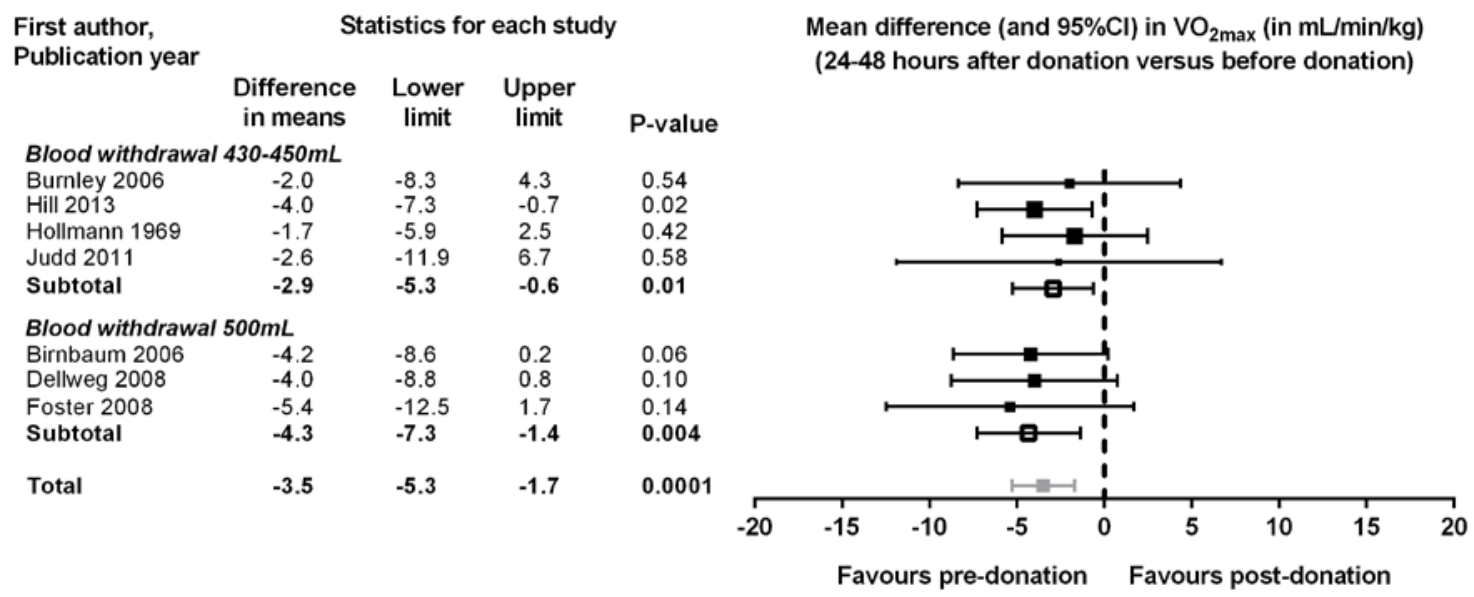

Figure 1. Study-specific mean differences (24-48 hr after donation vs. before donation) in $\mathrm{VO}_{2 m a x}$.

Mean difference of the respective study together with a $95 \% \mathrm{Cl}$. The size of the square represents the weight of the study in the meta-analysis. Weights are from random-effects analysis. 

together with a $95 \% \mathrm{Cl}$.

Secondly, as correctly pointed out by the reviewers, we removed the study by Ekblom et al. ${ }^{2}$ (i.e. 72 hours after donation) from this analysis and we corrected the blood volume withdrew (i.e. $500 \mathrm{~mL}$ instead of $400 \mathrm{~mL}$ ) and the number of participants (11 instead of 10) from the study by Birnbaum et al. ${ }^{4}$ However, the latter had minimal impact on the resulting 95\% confidence interval and no impact on overall statistical significance.

Finally, we believe that the study by Foster et al. ${ }^{3}$ is in line with our selection criteria and thus needs to be included in this systematic review. However, we agree with the reviewers that some confounding issues are present in this study. We can classify these issues under the domain 'limitations in study design’ in our quality assessment (cfr. GRADE methodology). Since downgrading the quality of the body of evidence due to limitations in study design was already performed, no further adaptations are needed, and these additions have no impact on the earlier determined level of evidence.

In summary, this subgroup analysis and corrections to some minor errors do not impact our earlier conclusions and support our main conclusion that a standard whole blood donation (ranging from 400-500 mL) leads to a small but potentially physiologically important reduction in $\mathrm{VO}_{2 m a x}$ in the first 2 days after the blood donation. A recent well-designed randomized controlled trial confirmed the reduction in $\mathrm{VO}_{2 \max } 2$ days after a (first) blood donation $(470 \mathrm{~mL})$, although this reduction was even smaller when taking into account a placebo group (5\% decrease in donation group versus $2 \%$ decrease in placebo group resulted in a true effect of $3 \%$ decrease). This finding showed that the decrease in $\mathrm{VO}_{2 \max }$ is not totally attributable to the donation itself, but also to fatigue induced by the exercise tests. ${ }^{5}$

Hans Van Remoortel, MSc, PhD

Emmy De Buck, MBE, PhD

Belgian Red Cross, Centre for Evidence-Based Practice, Motstraat 42, 2800 Mechelen, Belgium There is no conflict of interest. 


\section{References}

1. Van Remoortel H, De Buck E, Compernolle V, et al. The effect of a standard whole blood donation on oxygen uptake and exercise capacity: a systematic review and meta-analysis. Transfusion 2017;57:451-62.

2. Ekblom B, Goldbarg AN, Gullbring B. Response to exercise after blood loss and reinfusion. J Appl Physiol 1972;33:175-80.

3. Foster C, Porcari JP, Anderson J, et al. The talk test as a marker of exercise training intensity. J Cardiopulm Rehabil Prev 2008;28:24-30; quiz 1-2.

4. Birnbaum L, Dahl T, Boone T. Effect of blood donation on maximal oxygen consumption. J Sports Med Phys Fitness 2006;46:535-9.

5. Meurrens J, Steiner T, Ponette J, et al. Effect of Repeated Whole Blood Donations on Aerobic Capacity and Hemoglobin Mass in Moderately Trained Male Subjects: A Randomized Controlled Trial. Sports Med Open 2016;2:43. 